\title{
La (des)cortesía en el ámbito político: estudio del debate electoral español de 2019
}

\section{(Im)politeness in Politics: Study of the Spanish Electoral debate 2019}

Susana Ridao Rodrigo*

*Universidad de Almería (UAL), La Cañada de San Urbano, Almería / España sridao@ual.es

https://orcid.org/0000-0002-1109-655X

\begin{abstract}
RESUMEN: El objetivo de este artículo se centra en analizar las tipologías discursivas sobre la (des)cortesía utilizadas por cuatro políticos españoles: Pablo Casado, Pedro Sánchez, Pablo Iglesias y Albert Rivera. El corpus examinado es el debate electoral que tuvo lugar el 28 de abril de 2019. Como resultado destaca que las categorías más empleadas fueron: la cortesía valorizadora directa de halagos $(33,18 \%)$ cuando hablan de su propio partido político, la descortesía al referirse a partidos políticos rivales, en particular, la descortesía negativa (30,63\%), la descortesía descarnada $(17,89 \%)$ y la descortesía grosera $(14,39 \%)$.
\end{abstract}

PALABRAS CLAVE: (des)cortesía, pragmática, política, debate electoral.

ABSTRACT: This paper analyzes the discursive typologies about (im)politeness used by four Spanish politicians: Pablo Casado, Pedro Sánchez, Pablo Iglesias and Albert Rivera. The corpus examined is the electoral debate that took place on April 28, 2019. As a result, it highlights that the categories most used are: the direct politeness value of flattery $(33.18 \%)$ when they talk about their own political party, and impoliteness when referring to rival political parties, in particular, negative impoliteness $(30.63 \%)$, bald on record impoliteness $(17.89 \%)$ and rude impoliteness $(14.39 \%)$.

KEYWORDS: (im)politeness, pragmatics, politics, electoral debate.

\section{Introducción}

Desde la Antigüedad, el hombre no solo ha reflexionado sobre el poder de convicción que ostentan los buenos oradores, sino sobre la importancia de las relaciones sociales a la hora de lograr los objetivos individuales. En los inicios de la oratoria, los contextos políticos demostraron que la ejecución 
del discurso resulta fundamental para fortalecer o debilitar la credibilidad del orador. Precisamente, con estas palabras culmina Platón su carta IV: "Ten en cuenta también que algunos opinan que eres menos amable de lo conveniente; no olvides que el agradar a las gentes es el medio de conseguirlo todo, mientras que la altanería lleva por compañera la soledad. Buena suerte" (PLATÓN, 1993, p. 54).

En España, el Centro de Investigaciones Sociológicas, en el macrobarómetro de marzo de 2019 sobre el estudio preelectoral a las elecciones generales, sostiene la existencia de un $41,9 \%$ de los encuestados con voto indeciso (2019, p. 5), lo que implica el número más elevado de voto indeciso en ese país desde que se hace seguimiento de tal cuestión. Para este porcentaje tan alto de población que todavía no ha decidido a qué partido político va a apoyar, la comunicación empleada por los representantes políticos juega un papel indiscutible a la hora de determinar su voto, teniendo en cuenta la triple e indivisa estructuración de la comunicación verbal, la comunicación paraverbal y la comunicación no verbal, y, por supuesto, las estrategias de (des)cortesía de las que hagan uso, que les permitirá simpatizar, en mayor o menor medida, con los votantes. Según un artículo publicado en el diario La Razón el 25 de abril de 2019, el 70\% de los individuos con voto indeciso decidió a qué partido apoyaría en las urnas tras ver los debates electorales. Además, resulta indudable el papel que posee la televisión a la hora de difundir los discursos políticos en tanto que es un medio audiovisual, de ahí que los representantes deben adecuar su discurso al canal televisivo de manera ordenada y conforme a las preferencias de la audiencia (CARAMELO, 2020, p. 274).

Como era de esperar, muchos investigadores han analizado la comunicación en el ámbito político desde muy diversas perspectivas, como la sociología, las ciencias políticas, la comunicación, la psicología o la pragmática, entre otras. Puede entenderse que hay varios argumentos que justifican la elección de estos contextos comunicativos como objeto de análisis, entre los que destacan el hecho de que en estas situaciones los actores demuestran un buen dominio de la oratoria o bien que se trate de un discurso marcadamente persuasivo. Para los políticos, la utilización de estrategias propias de la cortesía conforma "(...) un mecanismo muy eficaz de transmisión y de construcción ideológica, al tiempo que de proyección, de una determinada imagen del líder que los utiliza" (ESCRIBANO HERNÁNDEZ, 2019, p. 32). 
En español, desde una perspectiva lingüística se han elaborado interesantes trabajos tomando como corpus el discurso político, como es el caso de Blas Arroyo (2009, 2010, 2013) sobre las preguntas utilizadas en tales contextos, Ridao Rodrigo (2009b), Pérez García (2014) y Fernández García (2017) sobre las estrategias de (des)cortesía, Fuentes (2013) sobre argumentación, (des)cortesía y género, Mancera y Pano (2013) y Vivas (2016) sobre comunicación en redes sociales, Brenes (2015) sobre la intensificación de la aserción y Alvarado y Cortés (2017) sobre la risa, por citar tan solo algunos trabajos de una extensa nómina.

Este artículo pretende analizar el tipo de estrategias de (des)cortesía utilizadas por los cuatro políticos españoles que participaron en el debate electoral celebrado el día 22 de abril de 2019: Pablo Casado (Partido Popular), Pedro Sánchez (Partido Socialista Obrero Español), Pablo Iglesias (Podemos) y Albert Rivera (Ciudadanos). En concreto, tras examinar las tipologías de categorías tanto relacionadas con la cortesía como con la descortesía, se aporta información numérica de la utilización que efectúa cada participante. Se parte de la hipótesis de que -como es frecuente en el discurso político- estos sujetos recurrirán a estrategias de cortesía cuando hablan de los logros conseguidos por su partido y de descortesía al abordar las actuaciones de los partidos contrincantes. Por tanto, se tienen en cuenta las siguientes preguntas de partida: ¿con qué frecuencia emplean estrategias relacionadas con la cortesía y la descortesía?, ¿cuáles son las subtipologías más frecuentes?, ¿tales subtipologías más asiduas son empleadas con una frecuencia similar por todos los participantes?, ¿existe un mayor uso de cortesía cuando transmiten los logros conseguidos por sus propios partidos y descortesía al tratar la gestión de los partidos rivales?

\section{Las investigaciones sobre la (des)cortesía}

Haverkate (1994) sostiene que el comportamiento humano no puede ser neutro, de lo que se deduce que las estrategias de (des)cortesía conforman elementos indisociables a la interacción verbal humana. Se ha de precisar que en el ámbito anglosajón existe una mayor tradición y fecundidad en el estudio de la (des)cortesía con respecto a los países hispanohablantes. Además, los primeros estudios -Lakoff (1973), Fraser y Nolen (1981), Leech (1983) y Brown y Levinson $(1978,1987)$ - se centran en la cortesía de manera que dejan a un margen la descortesía, si bien es cierto que de 
forma tangencial se puede entender que tratan la descortesía dado que lo que no resulta cortés suele ser descortés. En la década de los 1990 se empieza a analizar la descortesía de forma autónoma con respecto a la cortesía (PROUST, 2018, p. 97). Sifianou y Tzanne defienden que en el año 2008 se produce un cambio en esta tendencia, en el sentido de que a partir de esta fecha los investigadores se centran en mayor medida en dar explicación a los fenómenos relacionados con la descortesía (2010, p. 663).

Otra cuestión que se ha de asumir es que la descortesía no únicamente se limita al plano verbal, sino que posee una dimensión extralingüística (OSUNA, 2018, p. 6). A su vez, no se puede olvidar que "la descortesía verbal es, precisamente, una actividad de imagen” (DEL VALLE NÚÑEZ, 2018, p. 191). Para un correcto análisis de las estrategias de (des)cortesía resulta necesario tener en cuenta el género discursivo, el tema tratado o el contexto en que es emitido (GONZÁLEZ-SANZ, 2017, p. 116). Además, existen investigaciones (RIDAO RODRIGO, 2009a, p. 145-146; PANO, 2017, p. 556) que insisten en tener en cuenta la valoración que los receptores efectúan sobre el acto de habla en el plano de la cortesía o descortesía, de tal manera que puede haber discrepancias entre la intención del emisor a la hora de cifrar el mensaje y la interpretación que ha efectuado el receptor al descifrarlo; es decir, que ambos participantes pueden entender que ha habido cortesía o descortesía, o bien se ha emitido el mensaje con intención cortés pero se ha interpretado como descortés o, al contrario, el emisor ha querido resultar descortés aunque el receptor lo haya recibido como cortés.

Existe tradición en que los políticos empleen con asiduidad descalificaciones con respecto a sus rivales como una estrategia que les permite ganar la confianza de los votantes; es decir, hay predilección por manifestar las cuestiones negativas de sus adversarios políticos en lugar de explicar con detalle su propio programa electoral (BLAS ARROYO, 2009; RUSILLO, 2019, p. 36). Concluye Wells (1999) que el discurso de ataque es utilizado con mayor frecuencia por el partido político que está en la oposición, frente al partido que ostenta el poder. En una línea similar se sitúa el trabajo de Dailey, Hinck e Hinck (2008) al aseverar que la oposición centra su discurso en hablar de los errores cometidos por el partido político que está gobernando, mientras que el grupo que gobierna dirige sus críticas a las medidas políticas que proponen los rivales e incluso los datos que manejan tales contrincantes. 
El investigador que se considera pionero en el campo de la descortesía es Culpeper (1996, 2005), Culpeper, Bousfield y Wichmann (2003), quien tomando como base las cinco estrategias de cortesía diseñadas por Brown y Levinson $(1978,1987)$ las extrapola al campo de la descortesía:

A. Descortesía descarnada: aquellos actos de habla amenazantes emitidos por el hablante sobre la imagen del receptor que son cifrados sin ambigüedad, es decir, de forma clara y directa. Curiosamente en esta categoría Culpeper no aporta ningún ejemplo, cuestión que es justificada por Blas Arroyo (2001, p. 21) por la similitud de esta categoría con la descortesía positiva y la descortesía negativa;

B. Descortesía positiva: como su propio nombre indica, está enfocada en dañar la imagen positiva del alocutario;

C. Descortesía negativa: en esta categoría se incluyen las estrategias cuyo fin se acota a dañar la imagen negativa del receptor;

D. Descortesía sarcástica o figurada: se trata de enunciados irónicos en los que el emisor selecciona actos de habla en que está presente el humor de tal manera que amenaza la imagen del interlocutor sin intención de ofenderle;

E. Sin cortesía: en determinadas ocasiones el contexto requiere que se empleen estrategias de cortesía, si bien el hablante puede optar por no hacer uso de ellas, por lo que tal carencia de cortesía implica descortesía.

Culpeper subraya la importancia de factores contextuales a la hora de interpretar la descortesía y el grado de ofensa de la misma, así como la evaluación por parte del interlocutor sobre la intención o el propósito descortés de determinados actos de habla:

Impoliteness is a negative attitude towards specific behaviours occurring in specific contexts. It is sustained by expectations, desires and/or beliefs about social organisation, including, in particular, how one person's or group's identities are mediated by others in interaction. Situated behaviours are viewed negatively when they conflict with how one expects them to be, how one wants them to be and/or how one thinks they ought to be. [...] Various factors can exacerbate how offensive an impolite behaviour is taken to be, including for example whether one understands a behaviour to be strongly intentional or not (2010, p. 3233). 
Por supuesto, a la hora de evaluar si un acto de habla resulta (des) cortés es necesario tener en cuenta la siguiente reflexión: "One practical issue in tune with this line is that we have no direct way of reaching into the heads of the speakers/communicators to discover what they intended (and sometimes even communicators are not sure what they intended or construct the intention post hoc)" (CULPEPER; IGANSKI; SWEIRY, 2017, p. 9).

Otra investigación célebre en el campo de la descortesía fue ideada por Kaul (2005), en la que aportaba dos conceptos nuevos que- en consonancia metodológica con Culpeper (1996, 2005), Culpeper, Bousfield y Wichmann (2003) al extrapolar a la descortesía tipologías de la cortesía establecidas por Brown y Levinson (1978) - toma de Bravo (1999) los conceptos de afiliación y autonomía en el campo de la cortesía y los adapta para dar cuenta de las características propias de la descortesía. Tales categorías son: (1) la afiliación exacerbada, que consiste en elegir la descortesía a modo de defensa, por lo que el hablante es considerado adepto al grupo; y (2) la refractariedad, que responde a una actitud de rebeldía con las cuestiones opuestas de manera que el usuario hace uso de una autonomía exacerbada de ser visto como opositor al grupo. Del mismo modo, Kaul (2008) habla de siete tipologías de descortesía que pueden clasificarse en orden descendente fundamentadas tanto en el daño que representan como en la intención del emisor: (1) descortesía con intención cortés, (2) descortesía involuntaria, (3) autodescortesía, (4) cortesía con intención descortés, (5) disminución voluntaria de la cortesía esperada por el receptor, (6) silencio abrumador, y (7) descortesía de fustigación.

Por su parte, de Kienpointner (1997, 2008a, 2008b) destacan dos cuestiones: en primer lugar, la sistematización para analizar la descortesía establecida en torno a la grosería cooperativa y la grosería no cooperativa; y, en segundo lugar, la vinculación entre actos de habla y emociones en tanto que esta cuestión resulta determinante a la hora de evaluar la cortesía o la descortesía presente en un acto de habla. Se puede consultar esta clasificación en Kienpointner (1997): (1) grosería cooperativa, (1.1) descortesía con fines humorísticos o bromas, (1.2) grosería irónica o cortesía de broma, (1.3) grosería reactiva, (1.4) grosería sociable, (2) grosería no cooperativa, (2.1) grosería estratégica, (2.2) grosería competitiva en conversaciones privadas, y (2.3) grosería intergrupal. 


\section{Corpus y método}

El corpus aquí analizado es el debate electoral español que tuvo lugar el 22 de abril de 2019 y que fue emitido por el canal de televisión pública La 1 , con motivo de la celebración de las elecciones nacionales del 28 de abril de 2019. El debate estuvo moderado por Xabier Fortes - un conocido periodista español de 53 años- y tuvo una duración total de una hora y veintisiete minutos. En este encuentro participaron los cuatro partidos políticos con mayor participación en el Congreso: Partido Popular, Partido Socialista Obrero Español, Podemos y Ciudadanos. En representación de estos partidos asistieron, por orden, Pablo Casado, Pedro Sánchez, Pablo Iglesias y Albert Rivera. El debate empezó con una introducción de los cuatro candidatos y, como es habitual, acabó con el denominado "minuto de oro" para cada uno de los participantes. En medio de estas partes mencionadas se produjo el debate en sí, que temáticamente estaba dividido en cuatro grandes bloques: economía, pensiones, política territorial y posibles pactos y alianzas entre partidos.

Para establecer una taxonomía de las distintas categorías discursivas sobre (des)cortesía, se ha utilizado la empleada por Ridao Rodrigo (2018), la cual se hace eco de la seguida en Vivas Márquez y Ridao Rodrigo (2015), si bien incorpora dos categorías más en el plano de la descortesía. La publicación de Vivas Márquez y Ridao Rodrigo (2015) se apoya en Albelda (2005) a la hora de establecer las categorías relacionadas con la cortesía, mientras que para el plano de la descortesía toma como base los estudios de Culpeper (1996, 2005), Culpeper, Bousfield y Wichmann (2003) y Kienpointner (1997). Esta es la clasificación que hallamos en Ridao Rodrigo (2018) quien analiza las estrategias de (des)cortesía presentes en perfiles públicos de redes sociales de políticos españoles:

\section{A. Cortesía:}

1. Cortesía valorizadora directa;

1.1. Felicitaciones (CVDF);

1.2. Cumplidos y piropos (CVDC);

1.3. Saludos (CVDS);

1.4. Expresiones de ánimo y buenos deseos (CVDE);

1.5. Agradecimientos (CVDA);

1.6. Invitaciones y ofrecimientos (CVDI); 
1.7. Halagos (CVDH);

1.8. Propuestas (CVDP).

\section{B. Cortesía valorizadora indirecta:}

2.1. Manifestación de interés (CVII);

2.2. Manifestación de acuerdo (CVIA);

2.3. Bromas afiliadoras (CVIB).

\section{Descortesía:}

a. Descortesía descarnada (DD): cuando no hay lugar a dudas de que la intención del emisor es dañar la imagen del receptor;

b. Descortesía negativa (DN): en los casos en que la imagen negativa del interlocutor resulta perjudicada;

c. Descortesía sarcástica o figurada (DS): en realidad no existe intención de dañar la imagen del receptor, siendo la ironía un ejemplo de esta subtipología;

d. Sin cortesía (SC): aplicada a las situaciones que requieren el uso de cortesía;

e. Descortesía encubierta (DE): empleando para ello las implicaturas, da como resultado ser sumamente ofensiva;

f. Grosería sociable (GS): en los casos en que el grupo valora de forma positiva el hecho de recurrir a expresiones descorteses;

g. Descortesía grosera (DG): a veces la descortesía puede resultar tan agresiva y grosera que en realidad daña la imagen del emisor en lugar de dañar la imagen del receptor;

h. Descortesía sarcástica hiriente (DSH): en ocasiones, determinados mensajes perjudican seriamente la imagen del alocutario, aun habiendo sido cifrados con un velo de humor.

\section{Análisis y resultados}

\subsection{Dimensión cuantitativa}

En la Tabla 1 se detallan los resultados hallados en función de la tipología discursiva y el orador, aportando tanto la frecuencia absoluta como el porcentaje correspondiente. A su vez, también se facilitan datos totales. Dado que las intervenciones suelen ser bastante largas y con frecuencia en 
una misma intervención se suceden distintas tipologías, se ha procedido a contar el número de palabras que cada político ha utilizado para cifrar tales categorías discursivas.

TABLA 1 - Datos cuantitativos de las tipologías discursivas sobre (des)cortesía desglosados por los participantes.

\begin{tabular}{|c|c|c|c|c|c|c|c|c|c|c|}
\hline \multirow{2}{*}{} & \multicolumn{2}{|c|}{ Pablo Casado } & \multicolumn{2}{|c|}{ Pedro Sánchez } & \multicolumn{2}{c|}{ Pablo Iglesias } & \multicolumn{2}{|c|}{ Albert Rivera } & \multicolumn{2}{|c|}{ Total } \\
\cline { 2 - 13 } & $\begin{array}{c}\text { Frec. } \\
\text { Abs. }\end{array}$ & $\%$ & $\begin{array}{c}\text { Frec. } \\
\text { Abs. }\end{array}$ & $\%$ & $\begin{array}{c}\text { Frec. } \\
\text { Abs. }\end{array}$ & $\%$ & $\begin{array}{c}\text { Frec. } \\
\text { Abs. }\end{array}$ & $\%$ & $\begin{array}{c}\text { Frec. } \\
\text { Abs. }\end{array}$ & $\%$ \\
\hline CVDF & - & - & - & - & - & - & - & - & - & - \\
\hline CVDC & - & - & - & - & - & - & - & - & - & - \\
\hline CVDS & 6 & 0,12 & 4 & 0,04 & 2 & 0,05 & 12 & 0,25 & 24 & 0,13 \\
\hline CVDE & - & - & - & - & 15 & 0,37 & 29 & 0,61 & 44 & 0,25 \\
\hline CVDA & 6 & 0,12 & 34 & 0,81 & 67 & 1,69 & - & - & 107 & 0,61 \\
\hline CVDI & - & - & - & - & 11 & 0,27 & 26 & 0,55 & 37 & 0,21 \\
\hline CVDH & 1969 & 42,15 & 1689 & 40,44 & 954 & 24,07 & 1198 & 25,49 & 5810 & 33,18 \\
\hline CVDP & - & - & - & - & - & - & 31 & 0,65 & 31 & 0,17 \\
\hline CVII & - & - & - & - & - & - & - & - & - & - \\
\hline CVIA & - & - & 7 & 0,16 & 26 & 0,65 & 7 & 0,14 & 40 & 0,22 \\
\hline CVIB & - & - & - & - & - & - & - & - & - & - \\
\hline DD & 919 & 19,67 & 863 & 20,66 & 483 & 12,18 & 869 & 18,49 & 3134 & 17,89 \\
\hline DN & 720 & 15,41 & 778 & 18,63 & 2046 & 51,62 & 1818 & 38,68 & 5362 & 30,63 \\
\hline DS & - & - & - & - & - & - & - & - & - & - \\
\hline SC & - & - & - & - & - & - & - & - & - & - \\
\hline DE & - & - & - & - & - & - & - & - & - & - \\
\hline GS & - & - & - & - & - & - & - & - & - & - \\
\hline DG & 1031 & 22,07 & 559 & 13,38 & 352 & 8,88 & 578 & 12,30 & 2520 & 14,39 \\
\hline DSH & 20 & 0,42 & 242 & 5,79 & 7 & 0,17 & 131 & 2,78 & 400 & 2,28 \\
\hline Total & 4671 & 100 & 4176 & 100 & 3963 & 100 & 4699 & 100 & 17509 & 100 \\
\hline
\end{tabular}

Al analizar la información relativa a los datos totales, se observa que es la cortesía valorizadora directa en halagos la categoría utilizada con mayor asiduidad (5810 en frecuencia absoluta y 33,18\%); seguida, con poca diferencia numérica, de la descortesía negativa (5362 en frecuencia absoluta y 30,63\%). En cambio, la descortesía descarnada presenta menor uso (3134 en frecuencia absoluta y 17,89\%) y por detrás se halla la descortesía grosera 
(2520 en frecuencia absoluta y 14,39\%). Hay otras categorías cuyo empleo resulta estadísticamente poco significativo: descortesía sarcástica hiriente (400 en frecuencia absoluta y 2,28\%), cortesía valorizadora directa de agradecimientos (107 en frecuencia absoluta y 0,61\%), cortesía valorizadora directa de expresiones de ánimo y buenos deseos (44 en frecuencia absoluta y $0,25 \%$ ), cortesía valorizadora indirecta de manifestación de acuerdo (40 en frecuencia absoluta y $0,22 \%$ ), cortesía valorizadora directa de invitaciones y ofrecimientos (37 en frecuencia absoluta y 0,21\%), cortesía valorizadora directa de propuestas (31 en frecuencia absoluta y $0,17 \%$ ) y cortesía valorizadora directa de saludos ( 24 en frecuencia absoluta y $0,13 \%$ ). Además, la cortesía valorizadora directa de felicitaciones, la cortesía valorizadora directa de cumplidos y piropos, la cortesía valorizadora indirecta de manifestación de interés, la cortesía valorizadora indirecta de bromas afiliadoras, la descortesía sarcástica, sin cortesía, la descortesía encubierta y la grosería sociable no se han utilizado ni una sola vez por ninguno de los cuatro oradores.

En el Gráfico 1 se aprecia la frecuencia de uso de las cuatro categorías discursivas más asiduas (tres de ellas vinculadas a la descortesía y una a la cortesía) en función de los participantes, con el fin de clarificar de manera visual dicha información.

GRÁFICO 1 - Frecuencia absoluta de las tipologías discursivas más utilizadas sobre (des)cortesía desglosadas por los participantes.

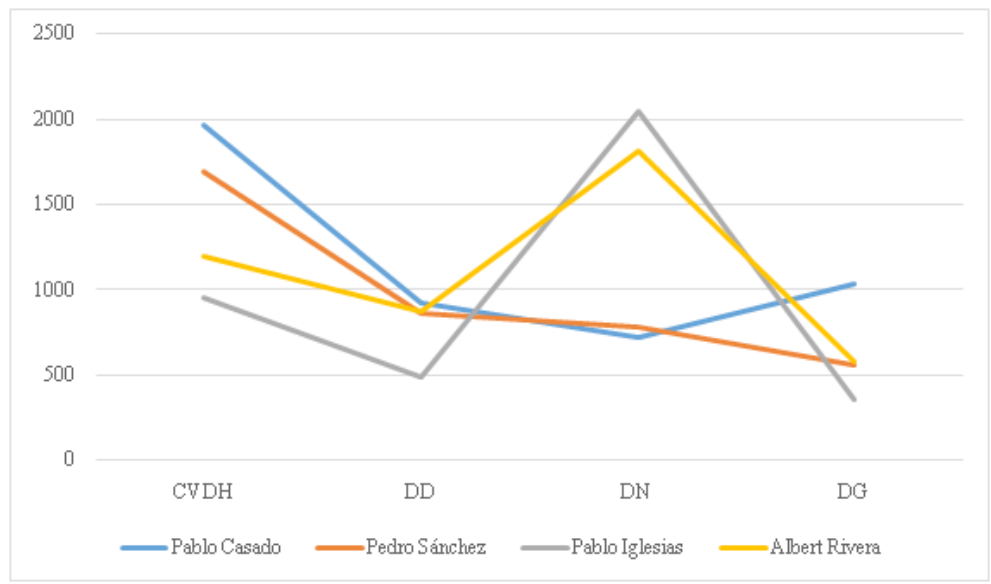


En el caso concreto de Pablo Casado, el líder del Partido Popular, se observa que es el participante que asume la cifra más alta en la categoría de cortesía valorizadora directa de halagos (1969 en frecuencia absoluta, lo que representa el 42,15\% de su discurso); a continuación, le sigue la descortesía grosera (1031 en frecuencia absoluta y 22,07\%), la descortesía descarnada (919 en frecuencia absoluta y 19,67\%) y la descortesía negativa (720 en frecuencia absoluta y 15,41\%). Por su parte, Pedro Sánchez -que representa al Partido Socialista Obrero Español- se decanta por utilizar con mayor asiduidad la cortesía valorizadora directa de halagos (1689 en frecuencia absoluta y 40,44\%), y en menor medida la descortesía descarnada (863 en frecuencia absoluta y 20,66\%), la descortesía negativa (778 en frecuencia absoluta y 18,63\%) y la descortesía grosera (559 en frecuencia absoluta y 13,38\%). En contraposición, el portavoz de Podemos, Pablo Iglesias, hace mayor uso de la descortesía negativa (2046 en frecuencia absoluta y 51,62\%), seguida de la cortesía valorizadora directa de halagos (954 en frecuencia absoluta y 24,07\%), la descortesía negativa (483 en frecuencia absoluta y $12,18 \%$ ) y la descortesía grosera (352 en frecuencia absoluta y $8,88 \%$ ). A su vez, el dirigente de Ciudadanos, Albert Rivera, también opta por emplear con más asiduidad la descortesía negativa (1818 en frecuencia absoluta y $38,68 \%$ ), quedando por detrás la cortesía valorizadora directa de halagos (1198 en frecuencia absoluta y 25,49\%), la descortesía descarnada (869 en frecuencia absoluta y 18,49\%) y la descortesía grosera (578 en frecuencia absoluta y $12,30 \%$ ).

\subsection{Dimensión cuantitativa}

En la Tabla 2 se recogen fragmentos de las cuatro categorías discursivas de (des)cortesía más utilizadas por los cuatro políticos sometidos a estudio, y también se añaden fragmentos de descortesía sarcástica hiriente que, aunque no es muy frecuente su empleo, sí resulta bastante significativo. 


\section{TABLA 2 - Datos cualitativos de las tipologías discursivas sobre (des)cortesía desglosados por los participantes.}

\begin{tabular}{|c|c|c|c|c|}
\hline & Pablo Casado & Pedro Sánchez & Pablo Iglesias & Albert Rivera \\
\hline $\begin{array}{l}\text { Cortesía } \\
\text { valorizadora } \\
\text { directa de } \\
\text { halagos }\end{array}$ & $\begin{array}{l}\text { [1] Bueno, } \\
\text { básicamente, } \\
\text { simplemente decir que } \\
\text { la tarjeta sanitaria } \\
\text { única está aprobada } \\
\text { y nosotros, además, } \\
\text { planteamos una cartera } \\
\text { básica de servicios. } \\
\text { Y lo que le tengo que } \\
\text { decir es que cuando el } \\
\text { Partido Popular ha } \\
\text { gobernado es cuando } \\
\text { los servicios sociales se } \\
\text { han garantizado. } \\
\text { (Contexto: } \\
\text { contestación a } \\
\text { Albert Rivera sobre } \\
\text { derechos sanitarios) }\end{array}$ & $\begin{array}{l}\text { [2] En el último año, en } \\
\text { estos } 12 \text { últimos meses, } \\
\text { se están creando } 1.483 \\
\text { empleos diariamente, } \\
\text { repito, } 1.483 \text { empleos } \\
\text { diariamente. } \\
\text { (Contexto: } \\
\text { contestación a } \\
\text { Albert Rivera sobre } \\
\text { la polémica tesis de } \\
\text { Pedro Sánchez) }\end{array}$ & $\begin{array}{l}\text { [3] Nosotros } \\
\text { pensamos que la gente } \\
\text { trabajadora, que los } \\
\text { autónomos, que la } \\
\text { pequeña empresa, } \\
\text { ya pagan muchos } \\
\text { impuestos y por eso } \\
\text { decimos que hay que } \\
\text { bajar el IVA a los } \\
\text { productos de primera } \\
\text { necesidad, que a los } \\
\text { productos veterinarios } \\
\text { se les tiene que reducir } \\
\text { el IVA, que a los } \\
\text { productos de higiene } \\
\text { femenina se les tiene } \\
\text { que reducir el IVA. } \\
\text { (Contexto: primera } \\
\text { intervención de } \\
\text { Pablo Iglesias en el } \\
\text { debate) }\end{array}$ & $\begin{array}{l}\text { [4] Miren, el dia que se } \\
\text { declaró la independencia de } \\
\text { Cataluña, la independencia } \\
\text { ilegal, yo estaba en el despacho } \\
\text { del Congreso y tenía que bajar } \\
\text { a hacer una rueda de prensa, y } \\
\text { creo que muchos catalanes que } \\
\text { me escuchen y muchos españoles } \\
\text { sabrán lo que digo, a mi se me } \\
\text { saltaron las lágrimas de ver } \\
\text { que en mi país daban un golpe } \\
\text { de Estado y que lo hacian en } \\
\text { el Parlamento de mi tierra, } \\
\text { de Cataluña, unos políticos } \\
\text { irresponsables rompiendo } \\
\text { un paísy rompiendo una } \\
\text { democracia. } \\
\text { (Contexto: primera } \\
\text { intervención de Albert } \\
\text { Rivera en el tercer bloque } \\
\text { dedicado a política } \\
\text { territorial) }\end{array}$ \\
\hline $\begin{array}{l}\text { Descortesía } \\
\text { negativa }\end{array}$ & $\begin{array}{l}\text { [5] Pero ¿votó usted a } \\
\text { favor de la congelación } \\
\text { o no? } \\
\text { (Contexto: } \\
\text { contestación a la } \\
\text { pregunta de Pedro } \\
\text { Sánchez sobre } \\
\text { la revalorización } \\
\text { de las pensiones } \\
\text { cuando gobierna el } \\
\text { PSOE y el PP) }\end{array}$ & $\begin{array}{l}\text { [6] Y, por cierto, señor } \\
\text { Casado, me gustaría que } \\
\text { les dijese a sus candidatos } \\
\text { y sobre todo a sus } \\
\text { candidatas que no es no y } \\
\text { que cuando una mujer no } \\
\text { dice si es no. } \\
\text { (Contexto: en esta } \\
\text { intervención está } \\
\text { hablando sobre } \\
\text { feminismo) }\end{array}$ & $\begin{array}{l}\text { [7] Por lo tanto, lo } \\
\text { que hay que hacer } \\
\text { con toda esa gente, } \\
\text { que es la mayoría de } \\
\text { los ciudadanos, es } \\
\text { bajarle los impuestos, } \\
\text { y nosotros hacemos } \\
\text { propuestas muy } \\
\text { concretas, de bajada del } \\
\text { IVA del } 10 \text { al } 4 \% \text { en } \\
\text { los suministros básicos. } \\
\text { (Contexto: } \\
\text { intervención en } \\
\text { el primer bloque } \\
\text { temático dedicado a } \\
\text { la economía) }\end{array}$ & $\begin{array}{l}\text { [8] Así que yo le pido que } \\
\text { cambien su política y que } \\
\text { Sucesiones, que la mantienen } \\
\text { en Galicia y en otros lugares, } \\
\text { que la quiten, como hemos } \\
\text { becho en Andalucía. } \\
\text { (Contexto: última } \\
\text { intervención de Albert } \\
\text { Rivera en el primer bloque } \\
\text { temático dedicado a la } \\
\text { economía) }\end{array}$ \\
\hline
\end{tabular}




\begin{tabular}{|c|c|c|c|c|}
\hline $\begin{array}{l}\text { Descortesía } \\
\text { descarnada }\end{array}$ & $\begin{array}{l}\text { [9] Pongo un ejemplo } \\
\text { muy concreto. El día en } \\
\text { el que el señor Sánchez. } \\
\text { llegó a la presidencia } \\
\text { del Gobierno en } \\
\text { España se creaban } \\
7.900 \text { empleos al } \\
\text { día, el día en que } \\
\text { convocó las elecciones } \\
\text { se destruían } 6.800 \\
\text { empleos al día. } \\
\text { (Contexto: } \\
\text { intervención en } \\
\text { el primer bloque } \\
\text { temático dedicado } \\
\text { a la economía) }\end{array}$ & $\begin{array}{l}{[10] \text { Es decir, la derecha }} \\
\text { no está proponiendo } \\
\text { menos impuestos a la } \\
\text { clase media trabajadora, } \\
\text { lo que está proponiendo es } \\
\text { menos impuestos para los } \\
\text { de siempre, para los de la } \\
\text { clase alta, y a cambio más } \\
\text { recortes y menos estado } \\
\text { del bienestarpara la clase } \\
\text { media y trabajadora. } \\
\text { (Contexto: en esta } \\
\text { intervención está } \\
\text { hablando de igualdad } \\
\text { económica) }\end{array}$ & $\begin{array}{l}\text { [11] Ya, pero la } \\
\text { pregunta no es al señor } \\
\text { Rivera, el señor Rivera } \\
\text { es de cualquier cosa, boy } \\
\text { dirá que acuerda con el } \\
\text { PPy mañana dirá que } \\
\text { acuerda con usted. } \\
\text { (Contexto: en } \\
\text { discusión con Pedro } \\
\text { Sánchez y Albert } \\
\text { Rivera) }\end{array}$ & $\begin{array}{l}\text { [12] No está aprobada, señor } \\
\text { Casado. Ustedes, y lo saben } \\
\text { los españoles que nos ven, un } \\
\text { español cuando se desplaza por } \\
\text { el territorio tiene burocracia, } \\
\text { dificultades, no hay receta } \\
\text { única ni expediente único. } \\
\text { (Contexto: contestación a } \\
\text { la intervención de Pablo } \\
\text { Casado quien afirma que } \\
\text { la tarjeta única sanitara } \\
\text { está aprobada) }\end{array}$ \\
\hline $\begin{array}{l}\text { Descortesía } \\
\text { grosera }\end{array}$ & $\begin{array}{l}\text { [13] El hábito no hace } \\
\text { al monje, un presidente } \\
\text { del Gobierno que } \\
\text { permite que le humillen } \\
\text { en su propia casa, } \\
\text { que es la de todos los } \\
\text { españoles, y que va a } \\
\text { Pedralbes, le reciben } \\
\text { como un jefe de Estado } \\
\text { y encima lo único que } \\
\text { cambia son las flores } \\
\text { de pascua para que no } \\
\text { sean amarillas, sino } \\
\text { rojas. } \\
\text { (Contexto: en esta } \\
\text { intervención está } \\
\text { hablando sobre } \\
\text { política territorial) }\end{array}$ & $\begin{array}{l}{[14] \text { Está diciendo que }} \\
\text { hay que tener armas } \\
\text { en casa, que hay que } \\
\text { suprimir las autonomias, } \\
\text { que esto de la violencia } \\
\text { de género es un cuento, } \\
\text { que el genocidio nazi es } \\
\text { un invento, que llevan } \\
\text { candidatos franquistas } \\
\text { declarados en sus listas } \\
\text { y dicen que van a cerrar } \\
\text { las televisiones que no les } \\
\text { gustan. } \\
\text { (Contexto: } \\
\text { intervención en } \\
\text { el último bloque } \\
\text { temático dedicado a } \\
\text { pactos) }\end{array}$ & $\begin{array}{l}{[15] \text { Al mismo tiempo }} \\
\text { acabemos con una } \\
\text { cosa que inventó un } \\
\text { gobierno socialista, que } \\
\text { es el llamado factor } \\
\text { de sostenibilidad, que } \\
\text { es como básicamente } \\
\text { decir a la gente que se } \\
\text { muera pronto porque si } \\
\text { se muere muy tarde el } \\
\text { sistema no es sostenible. } \\
\text { (Contexto: en esta } \\
\text { intervención está } \\
\text { hablando sobre } \\
\text { pensiones) }\end{array}$ & $\begin{array}{l}{[16] \text { ¿Sabe dónde está el }} \\
\text { milagro económico del } \\
\text { Partido Popular? En la } \\
\text { cárcel. } \\
\text { (Contexto: contestación a } \\
\text { Pablo Casado en el bloque } \\
\text { temático de economía) }\end{array}$ \\
\hline $\begin{array}{l}\text { Descortesía } \\
\text { sarcástica } \\
\text { hiriente }\end{array}$ & $\begin{array}{l}\text { [17] Está contestado, } \\
\text { es decir, el único que } \\
\text { ha dimitido ha sido el } \\
\text { director de Información } \\
\text { de Moncloa del señor } \\
\text { Sánchez. } \\
\text { (Contexto: en esta } \\
\text { intervención alude } \\
\text { a la corrupción) }\end{array}$ & $\begin{array}{l}\text { [18] En lugar de un } \\
\text { detector de mentiras, } \\
\text { babrá que poner un } \\
\text { detector de verdades a ver } \\
\text { si dicen alguna verdad. } \\
\text { (Contexto: } \\
\text { contestación a las } \\
\text { intervenciones } \\
\text { anteriores de Pablo } \\
\text { Casado y Albert } \\
\text { Rivera) }\end{array}$ & $\begin{array}{l}\text { [19] Que sí, señor } \\
\text { Rivera, claro que sí. } \\
\text { (Contexto: } \\
\text { contestación a la } \\
\text { intervención de } \\
\text { Albert Rivera quien } \\
\text { le ha reprochado } \\
\text { que Pablo Iglesias } \\
\text { es propietario de } \\
\text { un inmueble de alto } \\
\text { coste) }\end{array}$ & $\begin{array}{l}{[20] \text { En Andalucía le fue muy }} \\
\text { bien también. } \\
\text { (Contexto: contestación } \\
\text { a la intervención de } \\
\text { Pedro Sánchez quien } \\
\text { está hablando de política } \\
\text { territorial) }\end{array}$ \\
\hline
\end{tabular}


En primer lugar, habría que señalar que tan solo hay una categoría enmarcada dentro de la cortesía; en particular, se trata de la cortesía valorizadora directa de halagos, la cual es utilizada para dar buena imagen del grupo político al que pertenecen los participantes, si bien en el ejemplo 4 el líder de Ciudadanos se muestra más individualista al hablar de su reacción ante la declaración de la independencia de Cataluña. En el caso de la descortesía negativa, se puede cifrar mediante una pregunta (fragmento 5 de Pablo Casado), una sugerencia que en realidad debería ser entendida como un mandato (fragmento 6 de Pedro Sánchez), una orden transmitida mediante una perífrasis verbal de obligación (fragmento 7 de Pablo Iglesias) o una petición (fragmento 8 de Albert Rivera). A la hora de abordar la descortesía descarnada y la descortesía grosera se ha de reconocer que en determinadas intervenciones ha resultado complicada su distinción, dado que los participantes no dudan en dañar la imagen de sus adversarios de manera directa, como se puede interpretar al leer los ejemplos 9, 10, 11 y 12 que han sido catalogados como descortesía descarnada. En cambio, los extractos de descortesía grosera se caracterizan por ser excesivamente descorteses, hasta el punto de emitir mala imagen del orador y no centrar ese deterioro de imagen en las personas aludidas; de esta manera, en el fragmento 13 se utiliza el verbo "humillar", en el 14 el sintagma nominal "genocidio nazi", en el 15 el verbo "morir" y en el 16 el sustantivo "cárcel", si bien interpretado en su contexto se puede apreciar que son indudables las claras intenciones de los participantes de dejar en evidencia a los rivales. Para entender correctamente los ejemplos de descortesía descarnada hiriente es necesario el seguimiento de los acontecimientos (fragmento 17) o bien conocer el hilo de la conversación (fragmentos 19 y 20); sin embargo, el fragmento 18 destaca por contener una ironía que para ser entendida no necesita estar contextualizada.

Aunque con unos índices de empleo muy bajos, por lo que no resultan estadísticamente significativos, en el debate examinado se observan ejemplos de otras categorías discursivas relacionadas con la (des)cortesía que han de ser mencionadas. Tal es el caso de la cortesía valorizadora directa de agradecimientos:

[21] Yo le doy al señor Sánchez las gracias por reconocer a nuestro grupo parlamentario, que es verdad que ha jugado un papel muy importante en sacar adelante medidas sociales que han beneficiado al conjunto de los españoles. 
Una muestra de cortesía valorizadora de expresiones de ánimo y buenos deseos se puede encontrar en estas palabras de Albert Rivera, aunque están dirigidas a las víctimas de un atentado terrorista producido en el país asiático de Sri Lanka:

[22] Quiero dedicarles los primeros segundos a las víctimas del terrorismo en Sri Lanka, han muerto dos españoles, descansen en paz, y un abrazo para su familia.

El líder del Partido Socialista Obrero Español se sirve de este ejemplo de cortesía valorizadora indirecta de expresión de acuerdo, si bien es cierto que tan solo está indicando a Pablo Iglesias que en esos momentos el debate se centra temáticamente en política territorial:

[23] Creo que sí.

La cortesía valorizadora directa de invitaciones y ofrecimientos puede observarse en estas palabras pronunciadas por Albert Rivera con las que explícitamente está informando su intención de pactar con otro partido de derecha:

[24] Pero también en ese gobierno, que yo le tiendo la mano al Partido Popularpara que nos pongamos de acuerdo en formar un gobierno en coalición.

En este fragmento se aprecia que Albert Rivera hace gala de un discurso conciliador en el que tienen cabida los acuerdos conjuntos, de ahí que se considere una muestra de cortesía valorizadora directa de propuestas:

[25] Yo propongo ser el gobierno de los autónomos, que los autónomos sean los protagonistas de esta legislatura.

Ejemplos de la categoría de cortesía valorizadora directa de saludos se hallan precisamente al comienzo del debate. En particular, por este orden, Pablo Casado, Pedro Sánchez y Albert Rivera responden con el texto del fragmento 26, mientras que Pablo Iglesias lo cambia por un saludo más informal (fragmento 27):

[26] Buenas noches.

[27] ¿Qué tal? 


\section{Conclusiones}

De la presente investigación se obtienen ocho conclusiones principales:

1. Ya en la civilización griega los contextos políticos eran considerados escenarios propicios para hacer alarde de las dotes oratorias, de ahí que desde antaño estos ámbitos hayan captado la atención de investigadores de diversas disciplinas. En el caso del corpus sometido a estudio, el primer debate electoral español de 2019 para las elecciones a la presidencia del Gobierno destaca la existencia de un elevado porcentaje de voto indeciso: el 41,9\% de los encuestados (CENTRO DE INVESTIGACIONES SOCIOLÓGICAS, 2019, p. 5), por lo que la comunicación empleada por los participantes resulta decisiva para captar esos votos.

2. Aunque los primeros estudios sobre (des)cortesía se centraban en la cortesía y dejaban a un lado la descortesía, en los años 1990 se comienza a indagar la descortesía (PROUST, 2018, p. 97), y a partir de 2008 los investigadores empiezan a mostrar más interés por la descortesía (SIFIANOU; TZANNE, 2010, p. 663). Sin ir más lejos, los contextos políticos conforman corpus proclives para el análisis de la descortesía. Las investigaciones de referencia en descortesía son: Culpeper (1996, 2005, 2008, 2010, 2011), Culpeper, Bousfield y Wichmann (2003), Culpeper, Iganski y Sweiry (2017), Kaul (2005) y Kienpointner (1997, 2008a, 2008b).

3. El corpus aquí examinado está constituido por el debate electoral que se celebró el 22 de abril de 2019 con una duración de una hora y veintisiete minutos con motivo de las elecciones presidenciales en España del 28 de abril de 2019. En él participaron los líderes de los cuatro partidos políticos que ostentan mayor representación en el Congreso: Pablo Casado (Partido Popular), Pedro Sánchez (Partido Socialista Obrero Español), Pablo Iglesias (Podemos) y Albert Rivera (Ciudadanos). 
4. Para analizar las estrategias de (des)cortesía se ha recurrido a la taxonomía utilizada por Ridao Rodrigo (2018), la cual bebe de los trabajos de Albelda (2005) para la cortesía y Culpeper (1996, 2005), Culpeper, Bousfield y Wichmann (2003) y Kienpointner (1997) para la descortesía, si bien está complementada con categorías nuevas. En concreto, esta es la clasificación empleada en la presente investigación: (1) cortesía, (1.1) cortesía valorizadora directa, (1.1.1) felicitaciones, (1.1.2) cumplidos y piropos, (1.1.3) saludos, (1.1.4) expresiones de ánimo y buenos deseos, (1.1.5) agradecimientos, (1.1.6) invitaciones y ofrecimientos, (1.1.7) halagos, (1.1.8) propuestas, (1.2) cortesía valorizadora indirecta, (1.2.1) manifestación de interés, (1.2.2) manifestación de acuerdo, (1.2.3) bromas afiliadoras, (2) descortesía, (2.1) descortesía descarnada, (2.2) descortesía negativa, (2.3) descortesía sarcástica o figurada, (2.4) sin cortesía, (2.5) descortesía encubierta, (2.6) grosería sociable, (2.7) descortesía grosera, y (2.8) descortesía sarcástica hiriente.

5. En datos totales las categorías más asiduas son: cortesía valorizadora directa en halagos $(33,18 \%)$, descortesía negativa $(30,63 \%)$, descortesía descarnada $(17,89 \%)$ y descortesía grosera $(14,39 \%)$. No se registra ningún caso de cortesía valorizadora directa de felicitaciones, cortesía valorizadora directa de cumplidos y piropos, cortesía valorizadora indirecta de manifestación de interés, cortesía valorizadora indirecta de bromas afiliadoras, descortesía sarcástica, sin cortesía, descortesía encubierta y grosería sociable. El resto de las categorías presenta una frecuencia de utilización muy baja.

6. La cortesía valorizadora directa de halagos es la categoría discursiva más utilizada tanto por Pablo Casado (42,15\%) como por Pedro Sánchez (40,44\%), pues ambos tienen como denominador común haber estado en la presidencia del gobierno en los últimos años. Por el contrario, las fuerzas políticas de relativa nueva creación que no han ostentado el cargo de presidencia, esto es, Podemos y Ciudadanos, se decantan por un mayor uso de la descortesía negativa: Pablo Iglesias un 51,62\% y Albert Rivera un 38,68\%. 
7. El número de palabras que emite cada candidato resulta relativamente similar. Las cifras concretas por orden descendente son: Albert Rivera con 4.699 palabras, Pablo Casado con 4.671, y, con más diferencia, Pedro Sánchez con 4.176 y Pablo Iglesias con 3.963. Dentro de la cortesía, la subtipología de la cortesía valorizadora directa de halagos es la única que presenta valores de uso representativos, hasta el punto de alcanzar el 42,15\% en Pablo Casado, el 40,44\% en Pedro Sánchez, el 25,49\% en Albert Rivera y el 24,07\% en Pablo Iglesias. Por tanto, existe una mayor predisposición por el empleo de la descortesía: en cifras totales la descortesía negativa alcanza el 30,63\%, la descortesía descarnada el $17,89 \%$, la descortesía grosera el 14,39\% y la descortesía sarcástica hiriente el 2,28\%.

8. Estas preferencias de uso se justifican, de una parte, por el deseo de proyectar buena imagen de sí mismos, de ahí que recurran a la cortesía valorizadora directa de halagos, y, por la otra, la creencia de que hablando mal del adversario consiguen captar el voto de los espectadores, por eso, la descortesía es utilizada para dañar volitivamente la imagen de la persona o grupo al que hace referencia. Esta tesis es acorde con investigaciones como Ridao Rodrigo (2009b) y, más recientemente, Rusillo (2019). Además, el debate político es un contexto propicio para la expresión de las discrepancias de manera abierta: no solo por el género discursivo debate, sino también como consecuencia de que en política resulta habitual una comunicación en la que no se emplean atenuantes a la hora de transmitir disconformidad.

\section{Agradecimientos}

Este artículo es el resultado del proyecto de investigación "Variación pragmática en la expresión de la cortesía en español” (PR87/19-22547), financiado por el Instituto Seminario Universitario Menéndez Pidal (UCM), y del grupo de investigación HUM783, el cual está vinculado al centro de investigación CEMyRI de la UAL. 


\section{Referencias}

ALBELDA, M. La intensificación en el español coloquial. 2005. Tese (Doctorado en Filología Española) - Departamento de Filología, Universidad de Valencia, Valencia, 2005.

ALVARADO, M. B.; CORTÉS, L. M. La risa en los debates en torno al estado de la nación. Lingüística Española Actual, Barcelona, v. 39, n. 1, p. 5-30, 2017.

BLAS ARROYO, J. L. “No diga chorradas...”: La descortesía en el debate político cara a cara. Una aproximación pragma-variacionista. Oralia, [S.l.], v. 4, p. 9-46, 2001.

BLAS ARROYO, J. L. “¿Pero qué pregunta es esa?”: Sobre la naturaleza variable de preguntas y respuestas en el debate político-electoral. Oralia, [S.l.], v. 12, p. 153192, 2009.

BLAS ARROYO, J. L. La función de las preguntas en el discurso agonal: el debate electoral cara a cara. Discurso y Sociedad, [S.l.], v. 4, n. 4, p. 674-705, 2010.

BLAS ARROYO, J. L. Constraint Factors in the Formulation of Questions in Conflictual Discourse: An Analysis of Spanish Face-to-Face Election Debates. Pragmatics, [S.l.], v. 23, n. 2, p. 187-213, 2013. DOI: https://doi.org/10.1075/ prag.23.2.01bla

BRAVO, D. ¿“"Imagen positiva” vs. “imagen negativa”? Pragmática sociocultural y componentes de face. Oralia, [S.l.], v. 2, p. 155-184, 1999.

BRENES, E. La intensificación de la aserción en el Parlamento andaluz. Análisis pragmalingüístico de los verbos de opinión. Cultura, Lenguaje y Representación, Castellón, ES, v. XIV, p. 9-31, 2015.

BROWN, P.; LEVINSON, S. Universals in Language Use: Politeness Phenomena. In: GOODY, E. (ed.). Questions and Politeness. Strategies in Social Interaction. Cambridge: Cambridge University Press, 1978. p. 56-289.

BROWN, P.; LEVINSON, S. Politeness: Some Universals in Language Usage. Cambridge: Cambridge University Press, 1987. DOI: https://doi.org/10.1017/ CBO9780511813085

CARAMELO, L. M. Análisis del discurso emocional de Donald Trump en la campaña electoral de 2016. Ámbitos. Revista Internacional de Comunicación, Sevilla, v. 47, p. 267-287, 2020. DOI: https://doi.org/10.12795/Ambitos.2020.147.13

CENTRO DE INVESTIGACIONES SOCIOLÓGICAS. Macrobarómetro de marzo 2019. Preelectoral elecciones generales 2019. Estudio n. 3242, 2019.

CULPEPER, J. Towards an Anatomy of Impoliteness. Journal of Pragmatics, [S.l.], v. 25, p. 349-367, 1996. DOI: https://doi.org/10.1016/0378-2166(95)00014-3 
CULPEPER, J. Impoliteness and Entertainment in the TV Quiz Show: the Weekest Link. Journal of Politeness Research, v. 1, p. 35-72, 2005. DOI: https:// doi. org/10.1515/jplr.2005.1.1.35

CULPEPER, J. Reflections on Impoliteness, Relational Work and Power. In: BOUSFIELD, D.; LOCHER, M. (ed.). Impoliteness in Language. Studies on Its Interplay with Power in Theory and Practice. Berlín; Nueva York: Mouton de Gruyer, 2008. p. 17-44.

CULPEPER, J. Conventionalised Impoliteness Formulae. Journal of Pragmatics, [S.l.], v. 42, p. 3232-3245, 2010. DOI: https://doi.org/10.1016/j.pragma.2010.05.007

CULPEPER, J. Impoliteness: Using Language to Cause Offence. Cambridge: Cambridge University Press, 2011. DOI: https://doi.org/10.1017/ CBO9780511975752

CULPEPER, J.; BOUSFIELD, D.; WICHMANN, A. Impoliteness Revisited: with Special Reference to Dynamic and Prosodic Aspects. Journal of Pragmatics, [S.l.], v. 35, p. 1545-1579, 2003. DOI: https://doi.org/10.1016/S0378-2166(02)00118-2 CULPEPER, J.; IGANSKI, P.; SWEIRY, A. Linguistic Impoliteness and Religiously Aggravated Hate Crime in England and Wales. Journal of Language Aggression and Conflict, Amsterdam, v. 5, n. 1, p. 1-29, 2017. DOI: https://doi.org/10.1075/ jlac.5.1.01 cul

DAILEY, W.; HINCK, E.; HINCK, S. Politeness in Presidential Debates: Shaping Political Face in Campaign Debates from 1960 to 2004. Lanham: Rowman \& Littlefield, 2008.

DEL VALLE NÚÑEZ, C. Tuits: una respuesta descortés que produce la violencia de género. Oximora. Revista Internacional de Ética y Política, Barcelona, v. 13, p. 189201, 2018.

ESCRIBANO HERNÁNDEZ, A. La cortesía lingüística en el discurso político. Sintagma: Revista de Linguistica, Lleida, v. 31, p. 21-35, 2019.

FERNÁNDEZ GARCÍA, F. La descortesía en el debate electoral cara a cara. Sevilla: Editorial Universidad de Sevilla, 2017.

FRASER, B.; NOLEN, W. The Association of Deference with Linguistic Form. International Journal of the Sociology of Language, [S.l.], v. 27, p. 93-109, 1981. DOI: https://doi.org/10.1515/ijsl.1981.27.93

FUENTES, C. Argumentación, (des)cortesía y género en el discurso parlamentario. Tonos Digital, [S.l.], v. 25, p. 1-26, 2013. 
GONZÁLEZ-SANZ, M. Mecanismos de descortesía en la tertulia periodística de tema político. Cultura, Lenguaje y Representación, Castelló de la Plana, ES, v. XVIII, p. 103-119, 2017.

HAVERKATE, H. La cortesía verbal. Estudio pragmalingüístico. Madrid: Gredos, 1994.

KAUL, S. Descortesía intragrupal. Crónica en la interacción coloquial de clase media baja del español rioplatense. In: MURILLO, J. (ed.). Actas del II Coloquio Internacional del Programa EDICE. Actos de habla y cortesía en distintas variedades del español: perspectivas teóricas y metodológicas. Estocolmo: Servicio de Publicaciones de la Universidad de Estocolmo, 2005. p. 165-179.

KAUL, S. Tipología del comportamiento verbal descortés en español. In: BRIZ, A. et al. (ed.). Cortesía y conversación: de lo escrito a lo oral. Actas del III Coloquio Internacional del Programa EDICE. Valencia; Estocolmo: Universidad de Valencia, 2008. p. 254-266.

KIENPOINTNER, M. Varieties of Rudeness. Types and Functions of Impolite Utterances. Functions of Language, [S.l.], v. 4, n. 2, p. 251-287, 1997. DOI: https:// doi.org/10.1075/fol.4.2.05kie

KIENPOINTNER, M. Impoliteness and Emotional Arguments. Journal of Politeness Research, [S.l.], v. 4, n. 2, p. 243-265, 2008a. DOI: https://doi.org/10.1515/ JPLR.2008.012

KIENPOINTNER, M. Cortesía, emociones y argumentación. in: BRIZ, A. et al. (ed.). Cortesía y conversación: de lo escrito a lo oral. Actas del III Coloquio Internacional del Programa EDICE. Valencia; Estocolmo: Universidad de Valencia, 2008b. p. 25-52.

LAKOFF, R. The Logic of Politeness: Or, Minding Your P's and Q's. Papers from the Regional Meeting. Chicago Linguistic Society, Chicago, v. IX, p. 292-305, 1973.

LEECH, G. Principles of Pragmatics. Londres: Longman, 1983.

MANCERA, A.; PANO, A. El discurso político en Twitter. Análisis de mensajes que "trinan". Madrid: Anthropos, 2013.

OSUNA, R. (Des)cortesía y modalización en el contexto de educación básica. Praxis, Austin, v. 14, n. 2, p. 1-12, 2018. DOI: https://doi.org/10.21676/23897856.2763

PANO, A. La usurpación de la identidad con fines paródicos en la red social Twitter: ¿manifestaciones de descortesía verbal? Rilce: Revista de Filología Hispánica, Navara, v. 33, n. 2, p. 537-565, 2017. DOI: https://doi.org/10.15581/008.33.2.537-65 
PÉREZ GARCÍA, E. Deixis socialy (des)cortesía verbal como estrategias argumentativas. Análisis discursivo del debate político desde un enfoque sociopragmático. 2014. Tese (Doctorado) - Universidad de Murcia, Murcia, 2014.

PLATÓN. Cartas. Edición de José Torres Guerra. Madrid: Akal, 1993.

PROUST, V. Ironía y descortesía en los debates radiales de Chile: estrategias discursivas para ganar prestigio. Raled: Revista Latino-Americana de Estudos do Discurso, Brasilia, v. 18, n. 2, p. 93-109, 2018. DOI: https://doi.org/10.35956/v.18. n2.2018.p.93-109

RIDAO RODRIGO, S. Estrategias de (des)cortesía en mediaciones laborales. Murcia: Editum, Servicio de Publicaciones de la Universidad de Murcia, 2009a. DOI: https://doi.org/10.6018/editum.1421

RIDAO RODRIGO, S. "Y es que usted cambia de criterio cada cuarto de hora": Las estrategias de (des)cortesía en los debates españoles de 2008. Lingüistica en Red, Madrid, v. VII, p. 1-19, 2009b. DOI: https://doi.org/10.6018/editum.1421

RIDAO RODRIGO, S. (Des)cortesía en redes sociales: análisis cuantitativo de perfiles públicos de políticos españoles en Facebook y Twitter. Lingüistica Española Actual, Barcelona, v. XL, n. 2, p. 209-227, 2018.

ROJO, A. Siete de cada diez indecisos decantaron su voto tras los debates electorales. La Razón, Madrid, 25 de abril de 2019.

RUSILLO, M. Eufemismos, disfemismos y discurso político. 2019. Monografía (Fin de Grado en Estudios Ingleses) - Universidad de Jaén, Jaén, 2019.

SIFIANOU, M.; TZANNE, A. Conceptualizations of Politeness and Impoliteness in Greek. Intercultural Pragmatics, [S.l.], v. 7, n. 4, p. 661-687, 2010. DOI: https://doi. org/10.1515/iprg.2010.029

VIVAS, J. Imagen y (des)cortesía en las redes sociales en español. Un enfoque pragmático. 2016. Tese (Doctorado) - Universidad de Almería, Almería, 2016.

VIVAS, J.; RIDAO RODRIGO, S. Estrategias de (des)cortesía en redes sociales: análisis comparativo de Facebook y Twitter. Revista de Linguística, Lleida, v. 27, p. 73-87, 2015.

WELLS, W. T. An Analysis of Attacking, Acclaiming, and Defending Strategies in the 1976-1984 Presidential Debates. 1999. Dissertation (Ph.D.) - University of Missouri, Columbia, 1999.

Data de submissão: 23/03/2020. Data de aprovação: 08/10/2020. 